\author{
Fernando Amérigo \\ (profesor titular de Derecho Eclesiástico en la Universidad Complutense de \\ Madrid, Departamento de Derecho Internacional, Eclesiástico y Filosofía del \\ Derecho)
}

\title{
Diálogo interreligioso y gobernanza ciudadana *
}

\author{
Interreligious dialogue and citizen governance
}

\begin{abstract}
The 21st century has been characterized by the emergence of identity issues. The invocation of identity in a globalized world is on the agenda of all research centers and has generated a huge intellectual and political debate. Many of the conflicts that plague the contemporary world are based on identity. Exclusionary identitarianism, whether of a religious, ethnic or nationalist nature, has taken root in many societies. They are, as the writer Amin Maalouf called them, the "killer identities", exclusionary identities based on two fundamental concepts: the conception of an identity as unique, all-embracing of the individual, and the thesis of the scapegoat. The fight against these initiatives is complex and requires different instruments. One of these instruments, in the case of radicalized religious identities, could be the promotion by the public authorities of interreligious dialogue. These initiatives would be inserted in the new concept of governance and Open Government, which encourages citizen participation in the development of public policies. The current research formulates a proposal for the application of interreligious dialogue at the municipal level as a mechanism to combat religious radicalization and exclusionary identitarianism in the search for more plural and peaceful societies.
\end{abstract}

SUMARIO: 1. Introducción- 2. La problemática de las identidades - 3. El diálogo interreligioso como instrumento para la consecución de la convivencia pacífica y su promoción por el Estado -4. Diálogo interreligioso y gobernanza ciudadana.

\section{1 - Introducción}

En el año 1998 el escritor Amin Maalouf, premio Príncipe de Asturias de las Letras, escribía que "todas las matanzas que se han producido en los últimos años, así como la mayoría de los conflictos sangrientos, tienen que ver con complejos y antiquísimos contenciosos de identidad"1. Aun

\footnotetext{
* Articulo sometido a evaluación.
} 
cuando pueda parecer una afirmación excesivamente radical, lo cierto es que la cuestión identitaria se ha situado en la primera línea de las agendas de seguridad.

Así, Fukuyama nos dice que

"la identidad es el tema que subyace en muchos fenómenos políticos actuales, desde los nuevos movimientos nacionalpopulistas hasta los combatientes islamistas, pasando por las polémicas que tienen lugar en los campus universitarios" 2 .

Por su parte, Amartya Sen señala que

"si se estimula debidamente, la promoción de un sentido de identidad con un grupo de personas puede convertirse en una poderosa arma para tratar brutalmente a otro grupo. De hecho, muchos de los conflictos y las atrocidades se sostienen en la ilusión de una identidad única que no permite elección"3.

Y, en opinión de Luis Velasco,

"a lo largo de las últimas décadas el estudio de la asimilación de las identidades colectivas por parte de los miembros de las sociedades, ya sea de manera individual o gregaria, se ha convertido en un importante campo de estudio en todos los ámbitos de análisis de las Ciencias Sociales: politólogos, antropólogos, psicólogos e historiadores han identificado en el ámbito de creación de las identidades colectivas el origen de un gran número de conflictos políticos y sociales" ${ }^{\prime 4}$

La globalización ha supuesto un cambio notable en el marco de la sociedad mundial. Nuevos conflictos parecen aflorar y aun cuando sus causas políticas y económicas puedan parecer similares a la de siglos anteriores, es evidente que algunos de los grandes conflictos del siglo XXI se relacionan con un nuevo modo de entender el respeto a la identidad personal y a las identidades diferentes y con la búsqueda de un marco de convivencia pacífica entre ellas en una sociedad que cada vez es más multicultural. Identidad es un concepto relativamente vago sobre el que conviene reflexionar. Su fuerte componente personal hace de ella un

${ }^{1}$ A. MAALOUF, Identidades asesinas, Alianza editorial, Madrid, 2009, p. 44

2 F. FUKUYAMA, Identidad. La demanda de dignidad y las politicas de resentimiento, Deusto, Barcelona, 2019, p. 197.

${ }^{3}$ A. SEN, Identidad y violencia: La ilusión del destino, Katz, Madrid, 2007, p.15.

4 L. VELASCO MARTÍNEZ, Identidades colectivas en el horizonte 2050 ¿Consenso o disenso? El ejemplo del servicio militar, en Documento de investigación 24/2018, Instituto Español de Estudios Estratégicos, p. 8. 
concepto difuso y plural, distinto para cada persona. Sin embargo, la identidad no sólo se basa en la protección de una esfera personal libre de toda injerencia, sino que incluye el respeto a manifestarla y actuar conforme a ella. Por ello, la protección de la identidad ha tenido varios claros reflejos en el marco jurídico, que veremos a continuación.

En primer lugar, el respeto a la identidad de los individuos como una exigencia derivada del respeto debido a la dignidad de la persona, al libre desarrollo de la personalidad, al derecho de libertad de pensamiento, conciencia y religión y a todos los elementos que forman parte de su contenido nuclear esencial.

Aunque, como vemos, la presencia de las identidades y su impacto social se ha incrementado notablemente con la globalización, su configuración, tal y como hoy la entendemos, proviene de la modernidad: como ha señalado Kaufmann, "el proceso identitario está intrínsecamente ligado a la modernidad occidental" 5 .

Es evidente que, en los procesos de formación de los Estados, el poder político recurrió a la búsqueda de determinados elementos, religiosos, étnicos, lingüísticos, históricos y culturales que establecieran una determinada cohesión social para configurar las llamadas identidades nacionales.

En su origen, la tradicional homogeneidad que producía el sistema de Estado nacional en el modelo de protección de la identidad de los ciudadanos hacía suficiente el establecimiento de un marco de protección de la libertad, consistente en ser y actuar conforme a esa identidad y, con ello, una mera tolerancia a la existencia de identidades diferentes (libertad de pensamiento, conciencia y religión, libertad de expresión, etc.), que oscilaba entre un mayor o menor grado de reconocimiento según se permitieran o no las manifestaciones externas (en el aspecto religioso, por ejemplo, el culto). La plasmación jurídica de la protección de los derechos humanos actuaba como catalizador del respeto y ejercicio de la identidad. Ahora, con los efectos de la globalización, el problema fundamental que se les plantea a los ordenamientos jurídicos europeos no es sólo de reconocimiento del derecho, sino de conseguir que individuos y colectivos nuevos se integren en la sociedad, respetando su identidad, pero sin que ello suponga en ningún caso la violación de los derechos humanos, del sistema de valores que estos representan, o de las normas derivadas de ellos que regulan la convivencia democrática. Es decir, se requiere un

${ }^{5}$ J.C. KAUFMANN, Identidades. Una bomba de relojería, Ariel, Barcelona, 2015, p. 30. En el mismo sentido. F. FUKUYAMA, Identidad, cit., especialmente p. 52 y ss. 
respeto recíproco tanto de la sociedad de acogida de estos nuevos grupos identitarios cuanto de los nuevos grupos que se insertan en un tejido social ya conformado y respetuoso con el reconocimiento y ejercicio de los derechos fundamentales.

La presión y, en algunos casos, discriminación que producía la protección de la identidad homogénea en los Estados nacionales sobre las personas que no compartían esa identidad condujo a la necesidad de proponer fórmulas jurídicas para la protección de las minorías.

El concepto jurídico de minorías se ha relacionado con las llamadas identidades fuertes (etnia, lengua y religión). A través de su configuración, reconocimiento y protección, los individuos encontraron una fórmula jurídica que les permitía no solo tener su propia identidad, aunque no fuera la mayoritaria de la sociedad, sino también compartirla de forma solidaria con otras personas y preservar sus diferencias, pudiendo ejercitarlas externamente e incluso conservándolas a través de la transmisión a las generaciones futuras. Ese fue el esquema inicial de protección de las minorías de la Sociedad de Naciones, calificado por Wolfe como Human dynamite 6 . Como se ha señalado,

“el reconocimiento y la protección de los derechos de las minorías de conformidad con el Derecho Internacional empezó con la Sociedad de Naciones tras la finalización de la Primera Guerra Mundial. En el marco de esta Organización se instituyó un marco proteccionista de minorías de los países de Europa del Este y central compuesto por diversos instrumentos jurídicos [...] Aunque este sistema era ciertamente limitado - solo regía en ciertos Estados - no debe subestimarse su importancia, pues desplegaba sus consecuencias jurídicas en relación con las minorías en esos Estados. Además, constituyó un importante avance en la protección de los derechos de las minorías, precedente indiscutible del que ha sido el desarrollo posterior, tanto en el ámbito universal de Naciones Unidas, como en el ámbito regional - particularmente el europeo"7.

Para organizaciones internacionales, como Naciones Unidas o el Consejo de Europa, el establecimiento de marcos normativos que regularan el respeto de las minorías ${ }^{8}$ se basó fundamentalmente en encontrar

6 H.C. WOLFE, Human dynamite; the story of Europe's minorities, Foreign Policy Association, New York, 1939.

7 A.G. LÓPEZ MARTÍN, Las minorías en el contexto actual. Una aproximación a su marco jurídico internacional, en A.G. LÓPEZ MARTÍN y C. OTERO GARCÍA-CASTRILLÓN (Dirs.) Las minorías en el contexto actual, Dykinson, Madrid, 2021, pp. 16-17.

8 Declaración sobre los derechos de las personas pertenecientes a minorías nacionales 
construcciones jurídicas que permitan no sólo lo anterior, es decir, respetar las diferencias de estos grupos en un plano de igualdad formal, sino también establecer criterios jurídicos que acerquen su tratamiento a un modelo de igualdad material, lo que supuso comprometer a los Estados en el establecimiento de las condiciones necesarias para ejercerlas, a través de acciones positivas y políticas legislativas de reconocimiento. Por lo tanto, su regulación y protección se ha dirigido a construir un sistema de convivencia pacífica en el seno de sociedades cada vez más plurales.

El tratamiento jurídico de las minorías apuntaba a cuestiones fundamentales como la propia concepción de los Estados nacionales, la regulación jurídica del principio de igualdad y la lucha contra la discriminación, la titularidad individual o colectiva de los derechos fundamentales, la evolución del Estado liberal al Estado social, o la relación entre los conceptos de igualdad formal y material. La evolución sociopolítica de los últimos años a través de fenómenos como la globalización, los movimientos migratorios o el reconocimiento de la identidad cultural de diversos pueblos y colectivos, han situado a la problemática de las identidades en el centro de atención de cuestiones tan relevantes como el multiculturalismo, la interculturalidad, la integración de inmigrantes o de colectivos desfavorecidos, aspectos todos ellos relacionados con la igual dignidad de todos los seres humanos y con el propio concepto de ciudadanía.

El tratamiento de las identidades minoritarias resolvió algunas cuestiones de cohesión política, pero los fenómenos antes mencionados, el desarrollo de los derechos individuales y la aparición de populismos y nacionalismos de nuevo cuño han generado escenarios donde la incertidumbre y la volatilidad han convertido nuestras sociedades en más liquidas, y han provocado que las identidades, o más en concreto, las identidades excluyentes, de corte integrista y fundamentalista, se hayan convertido en una amenaza para la paz, la estabilidad y la cohesión política. Como señala la Estrategia Española de Seguridad de 2017, "la influencia de movimientos exclusivistas crece, pudiendo incluso tener un impacto negativo en la cohesión social y en la estabilidad política"9.

Como pone de manifiesto Fukuyama,

"la política de la identidad es la lucha por el reconocimiento de la

dignidad. Las democracias liberales se basan en el reconocimiento

o étnicas, religiosas y lingüísticas, Resolución AG 47/135 de 1992; Convenio marco para la protección de las minorías nacionales de 1995 del Consejo de Europa.

${ }_{9}$ Estrategia Española de Seguridad 2017 p., 34. 


\begin{abstract}
igualitario de la dignidad de cada uno de sus ciudadanos como individuos. Con el tiempo, la esfera de igual reconocimiento se ha expandido cuantitativamente en el número de personas aceptadas como ciudadanos con derechos, y cualitativamente en un significado cambiante del reconocimiento no solo como un derecho formal sino como una autoestima considerable. [...] La dignidad se democratizaba. Pero, en las democracias liberales, las políticas de identidad comenzaron a cambiar hacia formas colectivas e iliberales de identidad como nación y religión, ya que, con mucha frecuencia, los individuos no buscaban el reconocimiento de su individualidad, sino el reconocimiento de su semejanza con otras personas" 10 .
\end{abstract}

Esa transformación ha sido asumida por los discursos populistas, pero la política de la identidad no es mala de por sí; es una respuesta natural e inevitable a la injusticia. Solo se vuelve problemática cuando la identidad se interpreta o afirma de ciertas formas específicas ${ }^{11}$. Como señala Sen,

"no es posible suprimir o sofocar la invocación de la identidad en general [...] la identidad podría ser tanto una fuente de riqueza y de calidez como de violencia y de terror, y tendría poco sentido tratar la identidad en general como un mal"12.

\title{
2 - La problemática de las identidades
}

Desde esta perspectiva general, ahora ciñéndonos al aspecto religioso de la identidad, consideramos que la erradicación de la violencia, del odio y de los comportamientos discriminatorios, necesaria para la construcción de una paz estable, requiere un nuevo argumentario en el que conceptos jurídicos centrales, como el de la laicidad del Estado, deben desempeñar una función esencial, especialmente en lo relativo a la pluralidad de grupos y creencias religiosas. Es así porque, en el caso de la identidad religiosa, la laicidad, y más concretamente, el modelo de laicidad positiva trabaja en dos direcciones esenciales. Primero, con sus elementos de separación y neutralidad da pie a la existencia de nuevas identidades religiosas en un marco de igualdad formal. Segundo, porque el carácter positivo conlleva la actitud de los Estados a promover las condiciones y remover los obstáculos para que el ejercicio de esa identidad diferente sea real y efectiva (igualdad material).

${ }^{10}$ F. FUKUYAMA, Identidad, cit., p. 119.

${ }^{11}$ F. FUKUYAMA, Identidad, cit., p. 130.

12 A. SEN, Identidad, cit. p. 26. 
La conciencia de la propia identidad está integrada por las ideas y creencias que tiene el sujeto sobre sí mismo, sobre los otros y sobre el mundo, así como acerca de sus relaciones con ellos ${ }^{13}$. Cuanto más se multiplican las cuestiones, más nos hace falta encerrarnos en nuestras evidencias personales. La identidad es lo que cierra el sentido y crea las condiciones de la acción. Un sujeto sin identidad es un sujeto perdido psicológicamente, sin anclajes que justifiquen su existencia, deprimido, ciego mentalmente. Para Kaufmann, "el proceso identitario es una modalidad particular de la subjetividad en acción, consistente en fabricar a cada instante, una totalidad significativa"14. El individuo democrático del siglo XXI, como consecuencia del reconocimiento de sus derechos como ser humano, se ha hecho dueño de sí mismo, de forma que la identidad es la fuente de sentido y experiencia para la gente ${ }^{15}$.

En la conformación de la identidad personal se inmiscuye de forma significativa el concepto de pertenencia. Algunos elementos nos vienen dados al nacer (la etnia, la lengua, la nacionalidad), de forma que todos tendrían una identidad primaria o de nacimiento, pero esta no excluye sentir otras identidades como complementarias y no como contradictorias de la primera ${ }^{16}$. Otros elementos se conforman por nuestra experiencia vital, a la que hay que sumar las pertenencias por elección. De esta forma, en todos nosotros coinciden pertenencias múltiples que, a veces, se oponen entre sí y nos obligan a elegir ${ }^{17}$. Maalouf lo explica de la siguiente manera:

"No todas las pertenencias tienen la misma importancia, o al menos, no la tienen simultáneamente. Pero ninguna de ellas carece por completo de valor. Son los elementos constitutivos de la personalidad, casi diríamos que 'genes del alma', siempre que precisemos que, en su mayoría, no son innatos"18.

La promoción del libre desarrollo de la personalidad, de la capacidad del individuo de dar sentido a su propia existencia, ha propiciado lo que se puede denominar el "mercado de las identidades".

${ }^{13}$ D. LLAMAZARES, Derecho de la libertad de conciencia II. Conciencia, identidad personal y solidarida, Civitas, Thomson Reuters, Cizur Menor (Navarra), 2011.

14 J.C. KAUFMANN, Identidades, cit., p. 32.

15 J. CARRERA I CARRERA, Identidades para el siglo XXI, en Cuadernos CJ (www.fespinal.com) p. 9

16 J. CARRERA I CARRERA, Identidades, cit., p. 10.

17 A. MAALOUF, Identidades, cit., p. 12.

18 A. MAALOUF, Identidades, cit., p. 19. 
En el mundo actual, los individuos están expuestos a un amplio abanico de identidades. Las identidades se han convertido en un objeto más de consumo $^{19}$. Carrera lo expresa así:

"Construimos una identidad por aquello que consumimos, por aquello que vestimos ... Se crean así identidades colectivas que dan status social y que nos identifican como deportistas, como contestatarios, como jóvenes 'progres', como jóvenes 'fachas' [...] Nuestra capacidad de consumir, el tipo de marcas que compramos, nos hace entrar en una determinada subcultura que nos da identidad $\mathrm{y}$, por tanto, una cierta seguridad" 20 .

Por ello, coincidimos con Cruz en el carácter móvil, plástico y abierto de las identidades ${ }^{21}$. Porque, como afirma Maalouf,

"si bien en todo momento hay, entre los componentes de la identidad de una persona, una determinada jerarquía, ésta no es inmutable, sino que cambia con el tiempo y modifica profundamente los comportamientos" 22 .

$\mathrm{Y}$, en el mismo sentido, apunta Kaufmann que

"el papel creciente de las pasiones explica que las identidades sean cada vez más fluidas, incluso volátiles (y a veces hasta explosivas). El otro elemento es el carácter cada vez más subjetivo de la producción del sentido existencial. El crecimiento de esos dos elementos puede crear variaciones espectaculares de las afirmaciones identitarias" 23 .

Uno de los elementos que, a mi juicio, contribuye a la radicalización y al identitarismo excluyente es la concepción de que existe una identidad única, que niega la pluralidad de identidades dentro de uno mismo y que articula toda la experiencia vivida y los elementos heredados por nuestro nacimiento como hechos subordinados a esa identidad única. Como se ha señalado: "la insistencia, aunque solo sea implícita, en una singularidad no elegida de la identidad humana no solo nos empequeñece a todos, sino que hace que el mundo se torne mucho más inflamable"24. Fukuyama proclama que

${ }^{19}$ L. VELASCO MARTÍNEZ, Identidades colectivas, cit., p. 11.

${ }^{20}$ J. CARRERA I CARRERA, Identidades para el siglo, cit., p. 12.

${ }^{21}$ Cfr. M. CRUZ, Hacerse cargo. Por una responsabilidad fuerte y unas identidades débiles, Gedisa, Barcelona, 2015.

${ }^{22}$ A. MAALOUF, Identidades, cit., p. 22.

${ }^{23}$ J.C. KAUFMANN, Identidades, cit., pp. 59-60.

${ }^{24}$ A. SEN, Identidad, cit,. p. 41. 
"la regresión hacia comunidades cada vez más estrechas amenaza la deliberación y la acción colectiva de la sociedad en su conjunto. En última instancia, al final de este camino hallaremos la ruptura del Estado y el fracaso" 25 .

Sen, por su parte, añade que

"nuestras diferencias no descansan en una única dimensión [...] Cualquier persona es miembro de muchos grupos diferentes (sin que ello sea de ninguna manera una contradicción), y cada una de estas colectividades, a las que esa persona pertenece, le da una identidad potencial que -según el contexto- puede ser bastante importante"26.

Y nuevamente el politólogo estadounidense sentencia la cuestión así:

"Que naciera de determinada forma no significa que tenga que pensar de cierta manera; la experiencia vivida puede traducirse también en experiencia compartida. Las sociedades deben proteger a los marginados y a los excluidos, pero también debe marcarse objetivos comunes a través de la deliberación y el consenso. El cambio en la agenda de la izquierda y de la derecha hacia una mayor protección de identidades grupales cada vez más específicas, en última instancia amenaza la posibilidad de la comunicación y la acción colectiva" ${ }^{27}$.

Es evidente que somos cuando nacemos, pero también es cierto que somos en cuanto vivimos. Nuestra identidad nunca puede ser única, sino que es el resultado del conjunto de factores que modelan nuestra personalidad. Como señala Sen: "La religión no es, ni puede ser, la identidad omnicomprensiva de una persona"28. Se puede ser muy religioso, uno puede situar su identidad religiosa por encima de sus otras identidades, pero lo que no puede es eliminarlas, o negar que, aun teniendo menor importancia que la religiosa, no contribuyan a la conformación de la personalidad del ser humano.

En los integrismos, en las identidades excluyentes,

"lo que provocó que aquello que antes era un sentimiento de autoconocimiento haya mudado en instinto asesino es, en primer lugar, la determinación de ignorar la importancia de todas las otras filiaciones y asociaciones y, en segundo lugar, la redefinición de la identidad única en términos decididamente beligerantes. Aquí es

${ }^{25}$ F. FUKUYAMA, Identidad, cit., p. 179.

${ }^{26}$ A. SEN, Identidad, cit., p. 75.

${ }^{27}$ F. FUKUYAMA; Identidad, cit., p. 138.

${ }^{28}$ A. SEN, Identidad, cit., p. 118. 
donde terminan recalando la maldad y las confusiones conceptuales" 29 .

La identidad personal se va construyendo en el marco comunitario en el que está inserta la persona $\mathrm{y}$, al mismo tiempo, la identidad comunitaria también se va construyendo por la aportación de personas que se sienten identificadas con la comunidad ${ }^{30}$. Es evidente que no estamos solos. Podemos reconocer que la identidad se construye ante el reconocimiento de los otros ${ }^{31}$. Como ha señalado Trevor Dadson,

"la identidad no solo se forma en oposición al otro, sino también en relación con el otro. Un morisco puede creer que es más morisco cuanto más se opone a sus vecinos cristianos, cuanto más se diferencia de ellos, pero no puede evitar que siglos de convivencia (en el sentido de vivir juntos, lado a lado) afecten a su identidad y contribuyan a formar la persona que es" 32 .

Siguiendo a Manuel Castells ${ }^{33}$, podemos diferenciar las identidades colectivas como construcciones sociales dependiendo de su origen. Un primer tipo de identidad sería la identidad legitimadora, que se construye por las instituciones dominantes de la sociedad para extender y racionalizar su dominio respecto a otros actores sociales, como sería el caso, por ejemplo, de los "nacionalismos dominantes". Un segundo tipo sería la identidad de resistencia, generada por aquellos actores sociales que se encuentran en una situación discriminada o estigmatizada por la lógica de la dominación, de forma que, para sobrevivir, construyen barreras de resistencia al poder. Una tercera forma sería la identidad proyecto, en la que los actores sociales, sobre la base de ciertos materiales culturales, construyen una nueva identidad que redefine su posición en la sociedad buscando su transformación. Ejemplo de ello es el feminismo moderno. En todo caso las categorías son fluidas. Como advierte Carrera, "una identidad colectiva puede comenzar siendo de resistencia, para pasar

${ }^{29}$ A. SEN, Identidad, cit., pp. 233-234.

30 J. CARRERA I CARRERA, Identidades para el siglo, cit., pp. 9-10.

31 J. PIASTRO, Identidades en movimiento, en. M. CRUZ, (Coord.) Tolerancia o barbarie. Occidente ante el reto de la convivencia, Gedisa, Barcelona, 1998, p. 147.

32 T.J. DADSON Los moriscos entre el islam y el cristianismo: una identidad dividida, en R. GARcía CÁrcel Y E. SERRANO (eds.) Historia de la Tolerancia en España, Cátedra, Madrid, 2021, p. 146.

${ }^{33}$ M. CASTELLS, La era de la información, vol. 2, Alianza editorial, Madrid, 1997, p. 30 y ss. 
después a formular un proyecto y llegar a convertirse con el paso del tiempo, en identidad legitimadora" 34 .

La creación de un "nosotros" frente a "otros" que supone toda identidad colectiva, así como la pervivencia de ésta entre las sucesivas generaciones de un grupo, se ha convertido en un proceso mucho más complejo que antes en el mundo actual. La globalización ha desligado a los individuos de sus orígenes sociales, culturales, geográficos y religiosos, mientras que las propias prácticas sociales han variado mucho, generando complejidad en el seno de las sociedades ${ }^{35}$.

Como señala Manuel Cruz,

"en todo caso, si a alguien le llama la atención el presunto auge del nacionalismo en tiempos de globalización, tal vez habría que decir que esta circunstancia, lejos de provocar sorpresa, es precisamente la que explica tal auge. Sería, en efecto, la sensación de vértigo, de desamparo, de pérdida de cobijo que representaban las viejas comunidades fuertemente trabadas por vínculos ancestrales de todo tipo, la que explicaría el intento imaginario de reconstruir la vieja comunidad perdida" 36 .

La identidad actuaría como un remedio para escapar de la incertidumbre y la inseguridad. Es en ese contexto donde surgen las identidades colectivas de carácter excluyente, las que Amin Maalouf califica como "identidades asesinas". Surgen así los grupos integristas y fundamentalistas. Como señala Giddens, las personas a la intemperie dentro de una sociedad tan individualista como la nuestra se refugian en fundamentalismos para recuperar una identidad fuerte que les otorgue una seguridad psicológica ante las incertidumbres de un mundo cambiante ${ }^{37}$.

La globalización ha hecho que colisionen sociedades que no solo son diferentes, sino que tampoco han vivido al mismo ritmo ${ }^{38}$. Lo que, sin duda, genera volatilidad, incertidumbre, inseguridad y finalmente miedo.

Kaufmann afirma, en este sentido, que:

"El peligro que acecha, por tanto, es el del fundamentalismo y el integrismo identitarios (el religioso no es más que una variante que,

${ }^{34}$ J. CARRERA I CARRERA, Identidades para el siglo, cit., p.10.

${ }^{35}$ L. VELASCO MARTÍNEZ, Identidades colectivas, cit., p. 7.

${ }^{36}$ M. CRUZ, Hacerse cargo, cit., p.20.

${ }^{37}$ Cfr. A. GIDDENS, Un mundo desbocado. Efectos de la globalización en nuestras vidas. Taurus, Madrid, 2000, cap. 3.

${ }^{38}$ J. C. KAUFMANN, Identidades, cit., p. 41. 
cuando uno se centra en ella, nos hace olvidar las desviaciones más próximas ordinarias): cuando todo lo que tiene sentido en la vida de repente se ve reducido únicamente a la nación (contra los extranjeros) o la raza" 39 .

Ciertamente el fundamentalismo yihadista de Al Qaeda o el ISIS ha supuesto una de las quiebras más importantes de la seguridad mundial desde los inicios del siglo XXI. Pero sería un error pensar que los problemas identitarios se reducen a cuestiones religiosas.

"Está en la mente de todos el aprovechamiento, por no decir la manipulación, que los nacionalismos de todo tipo han hecho del concepto -sobre todo en su variante de la identidad nacional- como instrumento para homogeneizar artificial y tendenciosamente las conciencias de la ciudadanía apelando a la sentimentalidad" 40 .

Como señala Kaufmann,

"allí donde se posa nuestra mirada en el planeta, asistimos hoy en día a la multiplicación de explosiones pasionales de individuos que se desviven reinventando ilusorias comunidades étnicas o religiosas cerradas sobre sí mismas, universos secesionistas opuestos a un enemigo que es un chivo expiatorio" 41 .

Esa creación del chivo expiatorio, la causa de todos los males que asolan una determinada comunidad, es una característica evidente en la construcción de las identidades excluyentes. Se apela entonces a un imaginario colectivo inexistente, construido sobre manipulaciones de todo tipo, capaz de eliminar al chivo expiatorio y retomar una sociedad idealizada que nunca ha existido.

A la configuración y fortalecimiento del concepto del chivo expiatorio ha contribuido la muy conocida teoría del choque de civilizaciones de Samuel Huntington ${ }^{42}$. Esta concepción, que fragmenta la sociedad mundial sobre la base de culturas diversas condenadas a enfrentarse y combatir entre sí, tanto por su supervivencia, cuanto por la hegemonía mundial, ha fomentado, a mi juicio, la polarización y el temor y el odio hacia el otro. Es curioso cómo una obra tan intelectualmente poco solvente, bajo mi punto de vista, y plagada de simplificaciones y errores manifiestos -valga como muestra el hecho de que, cuando define la

${ }^{39}$ J.C. KAUFMANN, Identidades, cit., p. 63.

${ }^{40}$ M. CRUZ, Hacerse cargo, cit., p. 22.

${ }^{41}$ J.C. KAUFMANN, Identidades, cit., p. 59

42 Cfr. S. HUNTINGTON, El choque de civilizaciones. Y la reconfiguración del orden mundial, Paidós, Barcelona, 1997. 
civilización hindú, olvida los más de 130 millones de musulmanes indios, que convierten a este país en uno de los que tiene mayor número de seguidores de esa religión- ha tenido, y sigue teniendo, tanto predicamento. No es difícil pensar que tras esa concepción polarizada del chivo expiatorio están algunas declaraciones populistas, como las de Donald Trump refiriéndose al virus SARS-CoV-2 como el virus chino, para hacer creer que la culpable de la pandemia ha sido la civilización china y que el último objetivo de esta es acabar con el modelo de vida americano, ocultando así su incompetencia en la lucha contra la pandemia.

Coincido con Amartya Sen cuando afirma que

"las teorías culturales o civilizacionales que hacen caso omiso del papel de 'otras`sociedades no solo limitan el horizonte intelectual de los 'viejos europeos' o los 'viejos estadounidenses' y dejan su educación fragmentada de un modo extraño, sino que también dan a los movimientos antioccidentales una sensación falaz de separación y conflicto que contribuye a dividir a las personas a lo largo de una línea de enfrentamiento 'Occidente-antioccidente' sumamente artificial“" 43 .

El gran problema que generan las identidades excluyentes es el ciclo de acción reacción que provocan. Como señala Kaufmann, "todo fundamentalismo se constituye contra un enemigo, e incita a ese enemigo a inventarse también su propio fundamentalismo, desencadenando un engranaje perverso" ${ }^{\prime 4}$.

"No podemos evitar pensar en nosotros mismos y en nuestras sociedades en términos de identidad. Pero debemos recordar que las identidades que residen en lo más profundo de nosotros no son fijas ni están definidas por el azar del nacimiento. La identidad se puede utilizar para dividir, pero también para integrar, como se ha hecho en el pasado. Ese será, -afirma Fukuyama- al final, el remedio contra la política populista de nuestros días" 45 .

Es necesario tomar medidas, reconocer errores. Karen Armstrong, que inicia su libro Campos de Sangre con el conocido pasaje del Génesis en el que el Señor le pregunta a Caín por su hermano Abel ${ }^{46}$, afirma en el Epílogo de su obra:

\footnotetext{
${ }^{43}$ A. SEN, Identidad, cit., p. 242.

44 J.C. KAUFMANN, Identidades, cit., p. 73.

${ }^{45}$ F. FUKUYAMA, Identidad, cit., p. 197.

46 Génesis 4:2, 8-10.
} 


\begin{abstract}
"Sin embargo, nuestras políticas han contribuido a crear una ira y una frustración generalizadas, y en Occidente somos en parte responsables del sufrimiento en el mundo musulmán, que Bin Laden supo explotar. ¿Soy el guardián de mi hermano?' Seguramente la respuesta ha de ser: $\mathrm{Sí}^{\prime \prime} 47$.
\end{abstract}

\title{
3 - El diálogo interreligioso como instrumento para la consecución de la convivencia pacífica y su promoción por el Estado
}

La lucha contra las identidades excluyentes, las identidades asesinas, es una cuestión compleja. No existe una única fórmula, ni soluciones fáciles. Deben producirse acciones en el ámbito político, económico, cultural y social. Y ello tanto a nivel nacional como internacional. No pretendo, ni tengo capacidad para ello, ofrecer una solución completa, pero sí para proponer un instrumento que, a mi juicio, pueda contribuir a mitigar el radicalismo y el integrismo en materia religiosa y contribuir a la construcción de una sociedad más tolerante y pacífica. Ese instrumento no es otro que el diálogo interreligioso.

Como señala Francesc Torradeflot:

"El diálogo interreligioso puede tener al menos un triple sentido:

1. En un mundo donde la diversidad de creencias y convicciones se acrecienta y se hace más visible, puede surgir la necesidad de explorar vías de comunicación entre las distintas tradiciones religiosas. Solo desde la comunicación y la confianza se podrán materializar la comprensión, el respeto y la armonía entre comunidades religiosas, tanto local como globalmente.

2. En un mundo que desea y busca la paz, la justicia, y la sostenibilidad, las creencias y convicciones pueden aportar mucho en términos de inspiración de respuestas creativas y de movilización de voluntades. Las tradiciones religiosas y las convicciones no religiosas comparten unos valores que resulta imprescindible reforzar y poner en práctica a través del diálogo y la cooperación.

3. En un mundo presidido a menudo por el cuestionamiento individual, el diálogo interreligioso y de convicciones permite a cada persona, de forma indirecta pero ineluctable, ahondar en sus raíces espirituales, su tradición y su proceso. Al mismo tiempo, aporta los

47 K. ARMSTRONG, Campos de Sangre. La religión y la historia de la violencia, Paidós, Barcelona, 2015, p. 430. 
beneficios innegables del conocimiento de otras tradiciones religiosas y convicciones" 48 .

El Diálogo interreligioso es un mecanismo dirigido a la consecución de la convivencia pacífica y a la construcción de la paz. Como señalara Hans Kung: "No habrá paz entre naciones sin paz entre religiones. No habrá paz entre religiones sin diálogo entre religiones" 49.

El objetivo, por tanto, del diálogo interreligioso es la construcción de la paz. No persigue ni el proselitismo, ni el sincretismo religioso, no pretende la creación de una única verdad universal, ni poner en duda las creencias de nadie, aprecia en condiciones de igualdad las creencias y convicciones de todos los seres humanos.

El origen del diálogo interreligioso lo encontramos en el marco de la Exposición Colombina celebrada en Chicago en 1893, en la que tuvo lugar la primera edición de lo que se denominó Parlamento Mundial de las Religiones. Cien años más tarde en 1993, se convocó, de nuevo en Chicago, otra reunión interreligiosa rebautizada como Parlamento de las Religiones del Mundo. Allí se presentó el documento. "Hacia una ética mundial: una declaración inicial". El texto señala unos principios éticos fundamentales, asumibles por todas las religiones: la no-violencia, el respeto a toda vida, la solidaridad, un orden económico justo, la tolerancia, un estilo de vida honrado y veraz, la igualdad y camaradería entre mujeres y hombres. La iniciativa tuvo continuidad en 1999, con la convocatoria de una nueva sesión en Ciudad del Cabo. En 2004, la ciudad elegida fue Barcelona, Parlamento que se produjo bajo la dirección de Raimon Panikkar. Posteriormente la iniciativa ha continuado en las ciudades de Monterrey (2007), Melbourne (2009), Utah (2015) o Toronto (2018).

Junto al Parlamento de las Religiones del Mundo, otras organizaciones no gubernamentales han contribuido a convertir el diálogo interreligioso en un movimiento universal, entre ellas, el Consejo para un Parlamento de las Religiones del Mundo, la Conferencia Mundial de Religiones para la Paz y la iniciativa de las Religiones Unidas. A ellos habría que sumar los centros establecidos en el seno de las propias confesiones como el Pontificio Instituto para el Diálogo Interreligioso, presidido por el sevillano Cardenal Miguel Ayuso o la Organización para la Cooperación Islámica -organización intergubernamental cuyos objetivos son religiosos.

48 F. TORRADEFLOT, Religiones y pluralismo. Las vías del diálogo interreligioso en España, Documentos del Observatorio del Pluralismo Religioso en España, N ${ }^{\circ}$ 3, Madrid, p. 5.

${ }^{49}$ H. KÜNG, Reivindicación de una ética mundial, 5a ed., Trotta, Madrid, 2002, p. 237. 
En el siglo XXI el diálogo interreligioso ha experimentado, a mi juicio, un cambio notable que ha supuesto un nuevo paradigma en su desarrollo y sus objetivos. Dos son las razones que han contribuido a ese cambio. De una parte, la implicación de los Estados, del sector público, en el diálogo interreligioso. Un proceso que comenzó en el Parlamento Mundial de las Religiones de Barcelona, al acudir al encuentro representantes de entidades locales, regionales y autonómicas, que entendieron la necesidad de implicarse en un proceso que incidía sobre la gestión de la diversidad.

Hasta ese momento, la participación de los Estados en el diálogo interreligioso se había producido de manera indirecta a través de Naciones Unidas. El claro compromiso de las Naciones Unidas a favor de la promoción activa y decidida del diálogo entre culturas y civilizaciones y del diálogo interreligioso como pilar central de una cultura de la paz tuvo un claro reflejo en la Declaración de la UNESCO sobre el Papel de la Religión en la Promoción de una Cultura de la Paz del año 1994, expresión de un consenso posible entre políticos y religiosos, cuyo artículo 23 afirmaba:

"Queremos construir una cultura de la paz basada en la no-violencia, la tolerancia, el diálogo, el entendimiento mutuo y la justicia [...]. Hacemos un llamamiento a las diversas religiones y tradiciones culturales a sumar esfuerzos y a colaborar para extender el mensaje de la paz"50.

Posteriormente, y también en el seno de Naciones Unidas, y por iniciativa del presidente del Gobierno español José Luís Rodríguez Zapatero, surgió la Misión de Naciones Unidas para la Alianza de Civilizaciones, cuyo Alto Representante es, en la actualidad, el español Miguel Ángel Moratinos. Junto a estas iniciativas se han creado otras organizaciones internacionales, entre las que quiero destacar al KAICIID, centro de diálogo interreligioso e intercultural de Viena, organismo creado por los Estados de Arabia Saudita, Austria y España, junto al Vaticano en condición de Estado observador. Igualmente me parece muy relevante el papel de la diplomacia de Emiratos Árabes Unidos para la firma por parte del Papa Francisco y el Gran Imán de Al-Azhar, Ahmad Al Tayyeb, del "Documento sobre la Fraternidad Humana por la Paz Mundial y la Convivencia Común", firmado en Abu Dabi el 4 de febrero de 2019

Como ha señalado Álvaro Albacete, Embajador de España en el KAICIID:

50 Cfr. F. ToRradeflot (ed.), Diálogo entre religiones. Textos fundamentales, Trotta, Madrid, 2002, p. 49. 


\begin{abstract}
"La religión puede ser útil para alcanzar ciertos objetivos que la religión comparte con la diplomacia [...] Salvaguardando el hecho de que se trata de realidades diferentes, que operan en ámbitos diferentes, con valores y principios propios, lo cierto es que ambas realidades pueden coincidir en objetivos y medios para alcanzarlos, y es entonces cuando se debe producir esa colaboración, y así alcanzar objetivos que son legítimos y deseables para ambas realidades" 51 .
\end{abstract}

Un ejemplo de esta afirmación fue el papel de facilitador de la Conferencia Episcopal de Colombia en el proceso de paz de aquel país ${ }^{52}$.

La segunda razón del cambio de paradigma del diálogo interreligioso es el de su personalización. Hoy en día, el diálogo religioso ha superado la visión de diálogo interconfesional entre líderes religiosos, para convertirse en un instrumento de ciudadanía, de todas las mujeres y hombres para la consecución de una convivencia pacífica en la construcción societaria. Ello ha significado una notable apertura, tanto respecto de sus protagonistas, cuanto respecto al contenido del propio diálogo, abriéndose, también, a aquella parte de la ciudadanía que carece de creencias religiosas. En este sentido, las Naciones Unidas afirman que uno de los desafíos más importantes de nuestro siglo es el diálogo entre quienes se consideran religiosos y quienes no ${ }^{53}$. Muestra de lo que digo es la afirmación contenida en el "Documento Sobre la Fraternidad Humana" cuando dice:

"En conclusión, deseamos que: esta Declaración sea una invitación a la reconciliación y a la fraternidad entre todos los creyentes, incluso entre creyentes y no creyentes, y entre todas las personas de buena voluntad; sea un llamamiento a toda conciencia viva que repudia la violencia aberrante y el extremismo ciego; llamamiento a quien ama los valores de la tolerancia y la fraternidad" 54 .

La participación de un Estado democrático y laico, como el nuestro, en la promoción del diálogo interreligioso debe partir de determinados principios. Como pone de manifiesto Charles Taylor:

51 A. ALBACETE, Diplomacia y religión en la construcción de la paz, en Paz, conflicto y religión en el siglo XXI. Una visión prospectiva. Documentos de Seguridad y Defensa $\mathrm{N}^{\mathrm{o}} 76$, Instituto Español de Estudios Estratégicos, Ministerio de defensa, Madrid, 2017, pp. 158159.

${ }^{52}$ Cfr. A. ALBACETE, Diplomacia y religión, cit., pp. 159-160.

${ }^{53}$ F. TORRADEFLOT, Religiones, cit., p. 30.

${ }^{54}$ Documento Sobre la Fraternidad Humana, Abu Dabi, 2019. 


\begin{abstract}
"el secularismo implica una exigencia compleja. Con él se busca más de un bien. Podemos destacar tres, que se corresponden con las tres categorías de la trinidad de la Revolución francesa: libertad, igualdad y fraternidad. 1) Nadie debe ser coaccionado en materia de religión o creencias básicas. Esto es lo que normalmente se entiende por libertad religiosa - incluida, por supuesto, la libertad de no creer -. [...] 2) Debe existir igualdad entre personas con diferentes credos o creencias básicas: ninguna perspectiva religiosa y ninguna Weltanschauung (religiosa o arreligiosa) puede tener un estatus privilegiado, y aún menos ser doctrina oficial del Estado. Por último, 3) se debe escuchar a todas las corrientes espirituales y todas deben participar en el proceso siempre en marcha por el que la sociedad determina qué metas se propone (su identidad política) y cómo alcanzarlas (el concreto régimen de derechos y privilegios) [...] Naturalmente, estas metas pueden entrar en conflicto, a veces tendremos que buscar equilibrios entre bienes distintos. Además, creo que podríamos añadir una cuarta meta: que hagamos todo lo posible por mantener relaciones de armonía y civilidad entre quienes tienen diferentes religiones o Weltanschauungen (quizá es esto lo que habría que llamar fraternidad)"
\end{abstract}

Es decir, el diálogo interreligioso promovido por el Estado debe encuadrarse en el marco del principio de laicidad constitucional, que es el que garantiza la igual libertad de conciencia de todos los ciudadanos. De ahí que haya que ser respetuosos con los dos elementos esenciales de la laicidad. El primero de ellos es la neutralidad, que implica la imparcialidad de los poderes públicos frente a las convicciones y creencias de los ciudadanos, convirtiéndose de ese modo "en presupuesto para la convivencia pacífica entre las distintas confesiones religiosas existentes en una sociedad plural y democrática" 56 . De hecho, indica Taylor,

"la razón de ser de la neutralidad estatal es precisamente evitar favorecer o perjudicar no solo posturas religiosas, sino cualquier postura básica, religiosa o no. No podemos favorecer al cristianismo frente al islam, pero tampoco la fe religiosa frente a la increencia religiosa, ni viceversa" 57 .

Por su parte, el segundo elemento es la separación, por la que

55 C. TAYLOR, Por qué necesitamos una redefinición radical del secularismo, en E. MENDIETA, J. VANANWERPEN (eds), El poder de la religión en la esfera pública, Trotta, Madrid, 2011, pp. 39-40.

56 Sentencia del Tribunal Constitucional español 177/1996 de 11 de noviembre.

${ }^{57}$ C. TAYLOR, Por qué, cit., p. 41. 


\begin{abstract}
"el Estado se prohíbe a sí mismo cualquier concurrencia, junto a los ciudadanos, en calidad de sujeto de actos o de actitudes de signo religioso" 58 y "veda cualquier tipo de confusión entre fines religiosos y fines estatales" 59 . Y, además, "las confesiones religiosas en ningún caso pueden trascender los fines que les son propios y ser equiparadas al Estado, ocupando una igual posición jurídica"60.
\end{abstract}

De esta forma, el Estado debe actuar como facilitador neutral del diálogo interreligioso, sin que ello pueda suponer interferir en la autonomía interna de las confesiones, ni ejercer cualquier forma de regalismo para instrumentalizar a las confesiones religiosas o para proteger intereses espurios.

Si atendemos a lo establecido en el artículo 9.2 de nuestra Constitución, donde se encuentra el fundamento del principio constitucional de cooperación según nuestro Tribunal Constitucional61, el objetivo de la promoción del diálogo interreligioso sería, amén de promover condiciones y remover obstáculos para que el ejercicio de la libertad de conciencia de los individuos y los grupos en que se integra sea real y efectivo, facilitar la participación de todos los ciudadanos en la vida política, económica, cultural y social, como textualmente expresa el artículo citado. Como pone de manifiesto Habermas:

"En el discurso democrático los ciudadanos creyentes y no creyentes se encuentran en una relación complementaria. Unos y otros están implicados en una interacción que es constitutiva para un proceso democrático que surge de la base de la sociedad civil y se desarrolla gracias a las redes informales de comunicación de la esfera pública política"62.

\title{
4 - Dialogo interreligioso y gobernanza ciudadana
}

Llegados a este punto, e intentando haber dejado claro el papel del Estado como promotor del diálogo interreligioso, quisiera, antes de realizar una propuesta concreta, ligar el ejercicio del diálogo interreligioso con el

\footnotetext{
${ }^{58}$ Sentencia del Tribunal Constitucional español (STC) 24/1982 de 13 de mayo.

${ }^{59}$ Sentencia del Tribunal Constitucional español (STC) 177/1996 de 11 de noviembre.

${ }^{60}$ Sentencia del Tribunal Constitucional español (STC) 340/1993 de 16 de noviembre.

${ }^{61}$ Sentencias del Tribunal Constitucional español (SSTC) 46/2001 de 15 de febrero y 101/2004 de 2 de junio.
}

62 J. HABERMAS, Lo político: El sentido racional de una cuestionable herencia de la teología politica, en E. MENDIETA, J. VANANWERPEN (eds.), El poder, cit., p. 37. 
concepto de gobernanza. El término gobernanza viene utilizándose desde la década de los años 90 del siglo pasado para designar una nueva forma en las relaciones de poder ${ }^{63}$. El núcleo esencial de la gobernanza radica en la incorporación de la sociedad civil a la acción de gobierno ${ }^{64}$. Es evidente que entre los grupos que componen la sociedad civil están, entre otros, las confesiones religiosas ${ }^{65}$. La Comisión Europea afirma que: "La democracia depende de la capacidad de los ciudadanos para participar en el debate público"66 y entiende como principios de la buena gobernanza los de apertura, participación, responsabilidad, eficacia y coherencia ${ }^{67}$.

El informe de la Organización de las Naciones Unidas sobre la gobernanza de 1995 definió a esta como el conjunto de diferentes procesos y métodos a través de los cuales los individuos y las instituciones públicas y privadas, gestionan los asuntos comunes ${ }^{68}$.

"Para la Unión Europea, los derechos humanos son la piedra angular de las sociedades dinámicas e integradoras cuyos gobiernos trabajan en interés de la ciudadanía. La relación entre derechos humanos y gobernanza no es casual porque, cuando falla la gobernanza, el reconocimiento de los derechos humanos se debilita hasta el punto de que muchas personas no los ven reconocidos, especialmente las personas más vulnerables [...] Si no se da la buena gobernanza, se hace difícil -si no imposible - el respeto, protección y garantía de los derechos humanos por parte de los Estados"69.

El paradigma del Gobierno abierto, participativo y transparente recibió un notable impulso a través del documento elaborado en 2009 por el entonces presidente de los Estados Unidos de América Barack Obama,

63 I. MARTÍN SÁNCHEZ, Gobernanza y libertad religiosa en el Derecho Internacional universal, la Unión Europea, el Consejo de Europa y Latinoamérica, en Revista General de Derecho Canónico y Derecho Eclesiástico del Estado, N. 51 (2019), p. 2.

64 C. CLOSA MONTERO, El libro blanco sobre la gobernanza, en Revista de Estudios Políticos (Nueva Época), No 119, Enero-Marzo 2003, p. 488.

65 J.C. ALLI ARANGUREN, Gobernanza europea, en Monografías de la Revista Aragonesa de Administración Pública, XIV, pág. 20.

66 Comisión de las COMunidades Europeas, Bruselas 25-7-2001, COM (2001) 428 final La Gobernanza Europea. Un Libro Blanco, en Revista de Derecho de la Unión Europea, n. 61, semestre 2004, p. 261.

67 COMISIÓN DE LAS COMUNIDAdeS EUROPEAS, cit., pp. 259-260.

68 I. MARTÍN SÁNCHEZ, Gobernanza, cit., p. 2.

$69 \mathrm{DDHH}$ para la gobernanza (en www.prosalus.es/es/noticias/ddhh-para-la-gobernanza), p. 2. Citado por I. MARTÍN SÁNCHEZ, Gobernanza, cit., p. 3. 
titulado Memorandum for the Heads of Executive Departments and Agencies: Transparency and Open Government ${ }^{70}$.

Como se señala en el documento Gobernanza participativa local. Construyendo un nuevo marco de relación con la ciudadanía de la Federación Española de Municipios y Provincias:

"Las características que definen a la gobernanza participativa parten
de los valores del gobierno abierto, en tanto que nuevo paradigma de
la gestión pública que no solo ha revitalizado la participación
ciudadana, sino que la ha enriquecido al interrelacionarse con sus
otros dos pilares: la transparencia y la colaboración. Asumir que
dentro de las Administraciones públicas no se pueden encontrar
todas las respuestas a los problemas públicos y que se pueden
diseñar políticas y tomar decisiones de forma más efectiva y con
mayor calidad incorporando el saber colectivo, propicia la apertura
del sector público para colaborar con distintos actores -internos y
externos a la organización- con vistas a crear valor público
incorporando el conocimiento disperso bajo los esquemas de la
innovación abierta"71.

La construcción de una sociedad pacífica y tolerante es lógicamente un objetivo común tanto para las confesiones religiosas cuanto para los Estados. El diálogo interreligioso es un instrumento que puede contribuir, y de hecho contribuye, notablemente a la consecución de ese objetivo. Pero para el Estado, además, tiene otras implicaciones:

$1^{\circ}$. Contribuye al ejercicio real y efectivo de la libertad de conciencia, favoreciendo el ejercicio del derecho por parte de sus ciudadanos.

$2^{\circ}$ Inmiscuye a los ciudadanos en la buena gobernanza a través de uno de sus principios básicos, el de participación. En el caso español, además, cumple con el mandato contenido en el artículo 9.2 de la CE facilitando la participación de todos los ciudadanos en la vida política, cultural y social.

$3^{\circ}$ Contribuye al mandato del Tratado de Funcionamiento de la Unión Europea que establece la obligación de la Unión de mantener "un

70 Cfr. B. OBAMA, Memorandum for the Heads of Executive Departments and Agencies: Transparency and Open Government, 21 de enero de 2009 (recuperado de: https://obamawhitehouse.archives.gov/the-press-office/transparency-and-open-government).

${ }^{71}$ Cfr. E. HERNÁNDEZ (Coord.), Gobernanza participativa local. Construyendo un nuevo marco de relación con la ciudadanía, Federación Española de Municipios y Provincias; Red de Entidades Locales por la Transparencia y la Participación Ciudadana; Novagob. Lab, Madrid, 2018, p. 189. 
diálogo abierto, transparente y regular con las iglesias y las organizaciones filosóficas y no confesionales" 72 .

Así las cosas, entiendo que la promoción del diálogo interreligioso sería más una obligación para los Estados que una simple propuesta.

Para finalizar les voy a proponer una acción para implementar el diálogo interreligioso en el Estado español.

Mi propuesta parte de articular el diálogo interreligioso en el ámbito local. Se dice siempre que las políticas municipales, y no es un mero tópico, son las políticas más cercanas al ciudadano sin ningún género de dudas $\mathrm{y}$, posiblemente, las más indicadas para canalizar la participación hacia la buena gobernanza. Son las instituciones más cercanas a la ciudadanía dada su cercanía geográfica, el conocimiento personal que tienen muchos vecinos y vecinas de sus líderes locales (especialmente en municipios pequeños) y su concepción como primer recurso del sector público al que acuden las personas cuando necesitan obtener una respuesta o formular una petición ante la Administración, independientemente del reparto de competencias ${ }^{73}$. Como pone de manifiesto Torradeflot;

“Los políticos y/o profesionales o técnicos de la Administración municipal, autonómica o estatal pueden estimular o facilitar directa o indirectamente la creación de iniciativas interreligiosas en vistas a la cohesión social, especialmente en barrios y ciudades con gran diversidad cultural y religiosa, y cierto riesgo de comunitarización"74.

Esta iniciativa de promover el diálogo interreligioso en el ámbito municipal encaja perfectamente entre los objetivos que se establecen en la Carta para la Gestión Municipal de la Diversidad Religiosa, elaborada por la Fundación Pluralismo y Convivencia y la Federación Española de Municipios y Provincias. Los objetivos 6 y 7 de la Carta dicen lo siguiente:

“6. La adopción de mecanismos de consulta y participación de las comunidades religiosas para dar respuesta a las necesidades derivadas del ejercicio de la libertad religiosa, garantizar la integración de los grupos minoritarios y evitar situaciones conflictivas.

7. La promoción de espacios de diálogo y conocimiento mutuo entre las iglesias, confesiones y comunidades religiosas del municipio, así

\footnotetext{
72 Artículo 17 del Tratado de Funcionamiento de la Unión Europea.

73 E. HERNÁNDEZ (Coord.) Gobernanza, cit., p. 18.

${ }^{74}$ F. TORRADEFLOT, Religiones, cit., p. 19.
} 
como de éstas con otros sectores de la población y con el conjunto de la ciudadanía"75.

La propuesta encajaría además con la iniciativa Municipios por la Tolerancia, instada por las dos instituciones antes mencionadas con el apoyo del Instituto de Derechos Humanos de la Universidad de Deusto, y que fue presentada el 7 de mayo de 2021 por la entonces vicepresidenta primera del Gobierno de España Carmen Calvo.

La promoción del diálogo interreligioso en el ámbito municipal debería tener en cuenta, a nuestro juicio, los siguientes elementos:

$1^{\circ}$. Debería tratarse de un diálogo abierto al mayor número posible de grupos representativos. Lógicamente habría que intentar incluir a los representantes de las confesiones religiosas radicadas en cada municipio, pero también a otros grupos con concepciones globales del mundo de carácter no religioso que estén interesados en el dialogo con creyentes. Sería, por tanto, lo que se denomina un dialogo interconviccional76.

$2^{\circ}$. La iniciativa municipal debería conocer la evolución de los modelos de participación ciudadana, de forma que junto al modelo clásico de participación caracterizado por la presencia institucional, el protagonismo de los órganos formales y el papel central de los reglamentos, se tuviese en cuenta los elementos transformadores de la participación ciudadana en busca del paradigma del Gobierno Abierto, aprovechando las posibilidades del desarrollo de las TIC, lo que nos conduce al modelo contemporáneo de participación, caracterizado por el protagonismo de la tecnología, por la participación individual y por la flexibilidad o ausencia de reglamentación ${ }^{77}$.

$3^{\circ}$ En ese sentido, se trata de establecer un modelo de participación que incorpore la posibilidad de participación electrónica, lo que no quiere decir que deba sepultarse el modelo presencial, sino más bien al contrario: que ambos coexistan para aprovechar las virtudes de cada uno de ellos, adecuándose a las realidades y necesidades de cada caso ${ }^{78}$. Se podrá partir del modelo presencial mediante la participación de los representantes en cada municipio concreto, de los grupos religiosos radicados o presentes en el municipio y establecer además un cauce de participación electrónica abierto al conjunto de la ciudadanía, de forma que permita la participación abierta y flexible de todos los vecinos y vecinas interesados. Serían los

\footnotetext{
${ }^{75} \mathrm{Cfr}$. www. fundacionpluralismoyconvivencia.org.

76 Cfr. F. TORRADEFLOT, Religiones, cit., p. 23.

77 Cfr. E. HERNÁNDEZ (Coord.) Gobernanza, cit., p. 26 y ss.

78 Cfr. E. HERNÁNDEZ (Coord.) Gobernanza, cit., p. 28.
} 
responsables municipales los encargados de evitar que la participación abierta degenere en consecuencias no deseadas y dirigidas a manipular o dinamitar los procesos de participación y las finalidades que persigue.

$4^{\mathrm{o}}$. Una iniciativa como la que se propone requiere contar con un personal especializado en participación ciudadana y que tenga una visión precisa de los métodos actores, órganos e indicadores, de modo que se puedan realizar procesos adecuados y legitimados por su solvencia técnica ${ }^{79}$. Sería bueno en ese sentido que responsables municipales contaran con la experiencia de grupos de diálogo interreligioso con experiencia en el ámbito municipal como los promovidos por UNESCO ${ }^{80}$.

$5^{\circ}$. El objetivo de la promoción del diálogo interreligioso por iniciativa municipal es el de contribuir a la lucha contra la radicalización y el identitarismo excluyente buscando una mayor cohesión social. Es decir, la promoción de un mejor conocimiento, comprensión y colaboración de los miembros de las diferentes tradiciones religiosas que redunde en beneficio de toda la comunidad local, incluidos los grupos no religiosos, llevando la dimensión religiosa, de manera constructiva y positiva, a la vida en común de toda la comunidad local de manera integrada y normalizada, lejos de procesos de segregación comunitarista ${ }^{81}$.

$6^{\circ}$. La posición de los responsables municipales debe ser de absoluta neutralidad, ocupando una posición de promotores y mediadores del diálogo, evitando cualquier uso partidista o interesado políticamente del instrumento de diálogo, de forma que prevalezca, con carácter absoluto, el fin último de la iniciativa: combatir la posibilidad de radicalización o el uso violento de la identidad religiosa y asegurar una mayor cohesión social. Y ello con independencia de que el instrumento de diálogo pueda contribuir a conocer mejor los problemas de gestión de la diversidad religiosa existente en el barrio o en el municipio y generar respuestas adecuadas desde la responsabilidad municipal.

Una vez puesta en marcha la iniciativa y testados sus resultados, la promoción municipal del diálogo interreligioso podría adquirir una dimensión internacional, a través del establecimiento de una red internacional de municipios que promueven el diálogo interreligioso, lo que multiplicaría el efecto del dialogo desde la perspectiva municipal. En la medida en que la red internacional incorpore progresivamente a municipios con poblaciones diversas desde un punto de vista religioso, su

\footnotetext{
${ }^{79}$ Cfr. E. HERNÁNDEZ (Coord.) Gobernanza, cit., p. 34.

80 Cfr. F. TORRADEFLOT, Religiones, cit., p. 35 y ss.

${ }^{81}$ Cfr. F. TORRADEFLOT, Religiones, cit., p. 37.
} 
efecto multiplicador será mayor. Un objetivo de la red será, pues, alcanzar esa diversidad religiosa en su composición, de tal forma que el mosaico cada vez más colorido - permita no solo intercambiar buenas prácticas de gestión municipal de dialogo interreligioso, sino también hacerlo efectivo entre representantes municipales con la propia dinámica de la red. Para el establecimiento de esa red internacional, España cuenta con instrumentos internacionales (iniciativas diplomáticas) que pueden servir de plataforma de lanzamiento, en particular las ya mencionadas Alianza de Civilizaciones de Naciones Unidas y el Centro Internacional de Dialogo KAICIID.

A modo de conclusión, como afirma Charles Taylor:

"los regímenes que merecen ser calificados como 'seculares' (laicos en nuestra terminología) en la democracia contemporánea tienen que concebirse no primariamente como baluartes contra la religión, sino como intentos honestos de garantizar las tres (o cuatro) metas básicas que indiqué al comienzo. Y esto quiere decir que intentan configurar sus soluciones institucionales, no para mantenerse fieles a una tradición sacralizada, sino para maximizar las metas básicas de libertad e igualdad entre creencias básicas" 82 .

Es decir, tenemos que defender, además de los principios de Libertad e Igualdad, el de Fraternidad, el más olvidado de los principios ciudadanos.

Y coincido con el concepto que nos apuntaba el filósofo canadiense como aquello a lo que deberíamos llamar fraternidad: hacer todo lo posible por mantener relaciones de armonía y civilidad entre quienes tienen diferentes religiones o Weltanschauungen (concepciones globales del mundo).

${ }^{82}$ C. TAYLOR, Por qué, cit., p. 60. 